Obra
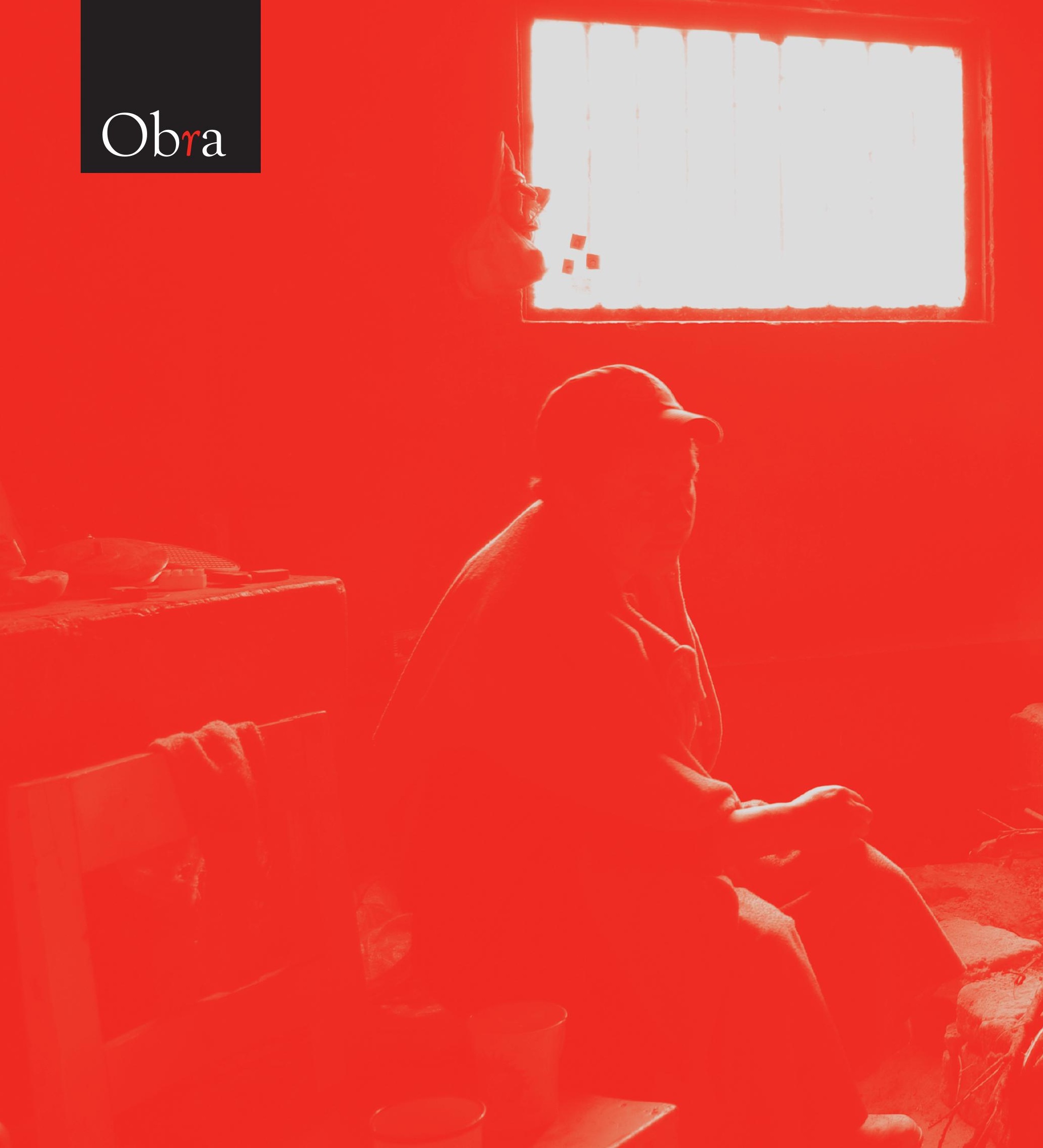


\section{¿QUÉ SON LAS "PRÁCTICAS ARTÍSTICAS COMUNITARIAS"? ALGUNAS REFLEXIONES PRÁCTICAS Y TEÓRICAS EN TORNO A LA CONSTRUCCIÓN DEL CONCEPTO}

David Ramos Delgado 
“Qué son las prácticas artísticas comunitarias?”

Algunas reflexiones prácticas y teóricas en torno a la construcción del concepto ${ }^{1}$

\section{Resumen}

Este artículo pretende hacer algunas reflexiones, cuestionamientos y aportes a propósito de la pregunta "iqué son las Prácticas Artísticas Comunitarias (PAC)?”, discutiendo lo problemático que resulta definirlas. Dado que sus acercamientos teóricos y producciones artísticas son tan diversos se termina en una aproximación al concepto diciendo qué aspectos $\mathrm{NO}$ son una PAC. Enunciando algunas características que intentan aportar al debate, como se verá, no se concluye en una definición precisa, pues solo se quiere hacer mención de varias consideraciones que han surgido del autor sobre el tema.

El texto se presenta en tres momentos: uno inicial que da cuenta de la perspectiva teórica que aquí se toma para tratar de situar "provisionalmente" el concepto de las PAC. Un segundo apartado se centra en describir y analizar el desarrollo de una PAC concreta, realizada con diez mujeres de la comunidad de Guatavita en torno a la re-construcción de memoria colectiva. Y, en una sección final se alude a algunas reflexiones surgidas desde este contraste entre teoría y práctica, concluyendo en esos aspectos, por negación, se intenta contribuir a la construcción del concepto de las PAC.

Palabras clave: Práctica Artística Comunitaria, Contexto, Comunidad, Re-significación, Artista, Espectador, Obra.

"What are the artistic community practices?"

Some practical and theoretical thoughts regarding the construction of their very concept Abstract

Through the question "What are the Artistic Community Practices (ACP)?" this paper aims at doing some reflections, queries and contributions on the subject, discussing as well the very issue of defining these practices. As their theoretical approaches and artistic productions are so diverse, it becomes necessary to try an approximation to the concept by defining first what an ACP is not, enunciating thus some of their characteristics, in order to enrich the debate. As it will be seen, it won't conclude with a precise definition, exposing instead the author's several considerations on the topic.

Through its development, the paper focuses on three different moments: in the first place, it gives an account of the theoretical perspective taken in order to render a provisional definition of the concept of ACP; then, the experience of an actual ACP -carried out by ten women of Guatavita's community on the subject of collective memory's reconstruction- is described and analyzed; finally, the last section provides some reflections aroused from the contrast between theory and practice, contributing thus to the construction of the concept of ACP.

Keywords: Artistic Community Practices, Context, Community, Re-signification, Artist, Viewer, Work.

“Que são as práticas artísticas comunitárias?” Algumas reflexões práticas e teóricas perto a construção do conceito.

\section{Resumo}

Este artigo tenta refletir, questionar e aportar a o propósito da pergunta "¿Que são as práticas artísticas comunitárias (PAC)?”, discutindo o problemático que e definir elas. Pelo fato das suas aproximações teóricas e produções artísticas serem tão diversas, se finaliza numa aproximação a o conceito dizendo que aspectos NÃO são uma PAC, enunciando algumas características que tentam aportar a o debate. Como dara para enxergar, não se conclui numa definição precisa, pois só se quer trazer algumas considerações que tem surgido do autor sobre o tema.

O texto se apresenta em três momentos: um inicial que da conta da perspectiva teórica que pega o texto para tentar situar "provisoriamente" o conceito da PAC; uma segunda parte centra-se em descrever e analisar o desenvolvimento de uma PAC concreta, feita com dez mulheres da comunidade de Guatavita em volta a reconstrução da memória coletiva; e numa seção final se alude a algumas reflexões surgidas desde estes contrastes entre teoria e prática, concluindo nestes aspectos que por negação, tentam contribuir na construção do conceito das PAC. Palavras chave: prática artística comunitária, contexto, comunidade, re-significação, artista, espectador, obra.

\footnotetext{
${ }^{1}$ Lo que viene a continuación emerge a propósito del proceso investigativo "Una Mirada al Ayer" Imaginarios y Memoria Colectiva: una Práctica Artística Comunitaria con diez mujeres del municipio de Guatavita”, llevado a cabo como proyecto de grado dentro de la Licenciatura en Arte Visuales de la Universidad Pedagógica Nacional. En este estudio se buscaba comprender los imaginarios que circulan en torno a la re-construcción de la memoria colectiva desde las historias de vida de cada una de las mujeres participantes en el desarrollo de un proceso creativo que partía del relato y algunos "dispositivos contenedores de memoria" (escritos, mapeos, etc.). El desarrollo de esta práctica artística comunitaria, estuvo articulada con el diseño investigativo biográfico-narrativo.
} 


\section{Las prácticas artísticas comunitarias: entre lo contextual y lo comunitario}

Desde algunas perspectivas se dice que el arte, en la actualidad, posee ciertas características que lo hacen pertinente para la sociedad. La existencia de unas claras y evidentes relaciones entre el arte y el contexto, por una parte, y entre el arte y lo comunitario por otro lado, se presentan como alternativas que intentan ver, en la experiencia artística, la posibilidad de involucrar al espectador de otra manera, entender la labor social del artista y armonizar perfectamente la obra y la realidad en la que se inscribe. Es desde estos dos "lugares", lo contextual y lo comunitario, que a continuación se espera puntualizar, con la intención de situar el concepto de práctica artística comunitaria (PAC). En ese sentido, por ejemplo, hay quienes hablan de un Arte Contextual (Ardenne, 2006) y desde esta óptica, un Arte Participativo que evoluciona a un Arte Relacional en los 90 (Bourriaud, 2006); también se refieren a la existencia de un Arte Público (Lippard, 2001) que, como se verá más adelante, se enlaza directamente con algunas características de las prácticas del Arte Comunitario (Palacios, 2009); otros hablan de las denominadas Gestiones Artísticas (Romero \& Giménez, 2005); y finalmente, se distingue una Estética de la Emergencia (Laddaga, 2006). Dejando esto claro, a continuación se hará una breve mención de algunas de estas perspectivas, presentándose algunos aspectos que de ellas interesa.

Hay que referirse a Ladagga (2006) quien reconoce una serie de prácticas emergentes que denomina como "ecologías culturales": una reorientación de las artes que evidencia un agotamiento del paradigma moderno, pues ya no responde a las necesidades de la sociedad actual; se basan en experiencias colaborativas entre grandes grupos de individuos que buscan "la invención de mecanismos que permitieran articular procesos de modificación de estados de las cosas locales y de producción de ficciones, fabulaciones e imágenes de manera que ambos aspectos se refuercen mutuamente" (Laddaga, 2006, pág. 8). Esta Estética de la Emergencia abarca prácticas de carácter solidario realizadas por alianzas entre personas que intentan generar cambios en el presente de una realidad concreta; este aspecto es fundamental a la hora de hablar de PAC, pues se estructuran desde este supuesto.

Por otro lado, se hace alusión a las Gestiones Artísticas, las cuales "surgen cuando los miembros de una colectividad estética detectan algún malestar del medio social y proponen su saber como solidario y transformador. Se ponen a disposición del 'deseo del Otro' reconociéndolo constitutivo del propio. Este 'nosotros' que valora la capacidad creadora de las comunidades y sus criterios de eficacia y equidad (...) cuestiona concepciones tradicionales del arte" (Romero \& Giménez, 2005, pág. 1). El reconocimiento del otro, la creación colectiva y la denuncia social, se hallan en la base constitutiva de las PAC y que aquí también es retomado como eje articulador.

$\mathrm{Al}$ principio de este apartado se habló de dos lugares que interesan enormemente: lo contextual y lo comunitario, lo cual fundamenta y soporta el concepto de PAC que se espera seguir. A continuación se profundiza en aspectos del arte contextual, del arte público y del arte comunitario, que ayudan a establecer esta relación entre contexto-comunidad.

\section{De lo contextual: entre lo participativo y lo relacional}

La primera de estas perspectivas, lo contextual, se puede entender como esa preocupación por establecer estrechos lazos entre la obra de arte y el "contexto" específico en que esta emerge, preocupándose por quién o quiénes la producen (actores), en dónde circula (escenarios), qué y cómo se hace 
(contenidos y medios). A esto es lo que se conoce como Arte Contextual, Ardenne (2006) uno de los autores más importantes en el momento de definirlo y clasificarlo, asegura que "un arte llamado contextual opta, por lo tanto, por establecer una relación directa, sin intermediario, entre la obra y la realidad" (pág. 11) o que "un arte llamado contextual agrupa todas las creaciones que se anclan en las circunstancias y se muestran deseosas de tejer ${ }^{2}$ con la realidad" (pág. 15).

Uno de los aspectos claves que distingue al arte contextual, según Ardenne (2006), radica en que el artista entiende la realidad más allá de la simple representación; lo artístico aquí se basa en "conectar" la obra con las características "reales" del "mundo real", es decir, a un espacio-tiempo concreto; por esto la catalogación de "contextual", porque existe un afán por integrar al contexto, es decir, a la "realidad vivida como una oferta de acontecimientos, como el referente que va a utilizar el artista a su antojo. De ahi esta última cualidad del arte contextual: un arte del mundo encontrado" (Ardenne, 2006, pág. 14).

De lo anterior, se desprende otro rasgo clave: el rechazo al museo y a la institucionalización de la obra. Gracias a la creación de estos vínculos con la realidad, el arte cobra otras formas de concebirse, de diversificarse y de alguna manera, garantiza una reconciliación con el mundo y el espectador olvidados a través del triunfo del museo en el trascurso de la historia, el arte había dejado de lado lo que ocurría a su alrededor (Ardenne, 2006).

Se le otorga importancia a la experiencia como aspecto fundamental para poder concebir el arte contextual en su contacto con lo real. El artista aquí intenta adentrarse e implicarse para lograr vivenciar completamente el contexto y poder actuar en él. Esta profunda comprensión de lo concreto y de lo local, también conlleva a pensar en la significación del acontecimiento como eje estructural, pues esta "naturaleza procesual" (Ardenne, 2006) contribuye a que el arte contextual permee con mucha más contundencia la realidad.

Todo lo anterior se evidencia en manifestaciones artísticas que tienen sus origen en las décadas de los 60 y 70 y que han evolucionado en los 80,90 y lo corrido de la primera década de este siglo. Aquello que podría clasificarse como arte contextual serían las obras que corresponden a: land art, arte de intervención, arte activista, performances, happenings, economics arts, el arte in situ, arte procesual, arte móvil o net art, arte participativo, arte relacional, entre otras tantas. Todas asumen diferentes perspectivas, con múltiples complejidades dependiendo de los medios empleados, del grado de participación del público o su cercanía con los lugares en el que se hacen; sin embargo apuntan siempre a la relación obra-realidad. Aquí se toman dos de estas perspectivas que, por sus características, pueden dar indicios para saber cuál es el lugar en el que se encuentran las PAC. Estas son el Arte Participativo y el Arte Relacional.

El Arte Participativo inicia con sus pioneros en los años 60 y 70. Puede entenderse como aquel que tiene su razón de ser en el espectador y su hacer activo como creador en la obra de arte. La construcción colectiva encaminada a una acción común es pues, la posibilidad para generar obras de carácter inacabado, procesual y democrático que exige la colaboración, implicación e intervención del "otro". Lo que fundamenta la experiencia en este tipo de obras de arte es que desde la participación del espectador y la intersubjetividad, se extiende a la construcción de un "estar juntos" (Ardenne, 2006).

\footnotetext{
${ }^{2}$ Aquí el autor hace referencia a la etimología del término "contexto" que quiere decir "la fusión", del latín contextus, de contex-tere, que significa "tejer con".
} 
Ardenne (2006) defiende claramente los postulados del arte participativo en sus inicios, asegurando que el Arte Relacional, en tanto evolución de lo "participativo" en los años 90, resulta un tanto problemático. Además de olvidarse de su compromiso político original y de banalizar los encuentros y la obra de arte al servicio del museo y la institucionalización, lo relacional se cataloga como algo completamente "novedoso", negando sus antecedentes históricos y su origen en los años 60 y 70 .

Independientemente de su vinculación con la institución, hay que resaltar algunos de sus postulados que se muestran como relevantes del arte relacional. Por su parte Nicolás Bourriaud (2006) lo define como "un conjunto de prácticas artísticas que toman como punto de partida teórico y práctico el conjunto de las relaciones humanas y su contexto social, más que un espacio autónomo y privativo" (pág. 142). Si esta definición se asocia con lo cotidiano y la condición intersubjetiva que posee el arte relacional, se puede decir que el intercambio humano, el diálogo y el encuentro dado en la participación del espectador, conllevan a hablar de la "elaboración colectiva del sentido" que la obra garantiza. La tipología de obras que propone Bourriaud (2006) desde esta óptica, oscilan entre las citas, los contratos, las colaboraciones, las relaciones profesionales con clientes, los intercambios entre las personas en las galerías o museos, y un sin números de acontecimientos con el otro que posibilitan el encuentro.

\section{De lo comunitario y lo público}

Una segunda perspectiva que ofrece ayuda al definir la manera como se quiere enfocar la idea de PAC, se refiere a lo comunitario. Varios autores han definido este aspecto como una de las principales características del Arte Público y del Arte Comunitario. Precisamente, Lucy Lippard (2001) define el arte público como "cualquier tipo de obra de libre acceso que se preocupa, desafía, implica, y tiene en cuenta la opinión del público para quien o con quien ha sido realizada, respetando a la comunidad y al medio" (pág. 61). Por otro lado Nina Felshin citada por Paloma Blanco (2001) asegura que "las discontinuidades sobre lo que se ha venido a llamar el nuevo género de arte público han incluido la noción de comunidad o de público como constituyentes mismos del lugar y han definido al artista público como aquel o aquella cuyo trabajo es sensible a los asuntos, necesidades o intereses comunitarios" (pág. 29). De este modo, la participación activa del público y las particulares del lugar, no solo referidas al espacio físico sino también a "lo humano", apuntan a que el arte se piense en su función social: preguntarse por lo que ocurre en lo colectivo.

En este mismo sentido y con relación al arte comunitario, Palacios (2009) asegura también que:

Gran parte de las prácticas actuales en relación con el arte público, se asocian al término arte comunitario o arte de la comunidad, traducido del término inglés: community art. En una genealogía del arte público, el arte comunitario sería el origen del 'arte público de nuevo género' (...). En relación con el arte público, el término arte comunitario se asocia aun tipo de prácticas que buscan una implicación con el contexto social que persiguen, por encima de unos logros estéticos, un beneficio o mejora social y sobre todo, que favorecen la colaboración y la participación de las comunidades implicadas en la realización de la obra (p. 198-199). 
Para algunos, el arte público de nuevo género, término acuñado por Suzanne Lacy, tiene sus antecedentes en el arte comunitario surgido en los 70 en Estados Unidos y Gran Bretaña, principalmente, en el que la preocupación por el contexto físico y social, y, el claro interés por implicar al espectador, son sus postulados principales (Palacios, 2009). Por su parte, Paloma Blanco (2001) propone dos genealogías que definen el desarrollo del arte público, del arte crítico, de las prácticas asociadas al activismo y la acción directa en Estados Unidos. La primera de ellas tiene que ver con su evolución con respecto a la relación entre el arte y los espacios públicos, donde la concepción de lugar se expande a las características del contexto; la otra tiene que ver con la trayectoria del arte crítico y su carácter político y activista, iniciado en los años 60 y 70, tomando mucha más fuerza en los años 80 y 90.

De todos modos, aquí interesa resaltar la manera como este arte quiere redefinir la noción de lugar, poniendo en tensión la especialidad contra la contextualidad. Más allá de refriere a los espacios físicos, lo que importa son los valores y significados humanos de esos espacios, así el lugar se muestra en su contextualidad para la creación. En consecuencia, "el lugar entendido como emplazamiento social con un contenido humano, [postula] la necesidad de un arte comprometido con los lugares sobre la base de la particularidad humana de los mismos, su contenido social y cultural, sus dimensiones prácticas, sociales, psicológicas, ecológicas, políticas..." (Lippard citada por Blanco, 2001, p. 31). En tanto el arte público y comunitario se insertan profundamente en el lugar, se preocupan por aspectos sociales pertenecientes a quienes ocupan el espacio.

Se ha esbozado ya la condición participativa y comunitaria que estas prácticas poseen por excelencia. Con respecto a esto se puede decir que es el espectador quien se sitúa en el centro de todo el proceso: es con él, para él y por él que la obra existe, pues en su concepción, su elaboración y su exhibición, todo el tiempo está inmerso. En palabras de Blanco (2001): "lo que nos interesa ahora no es simplemente la composición o identidad del público sino hasta qué grado su participación forma e informa la obra de arte, cómo funciona como parte integral de la estructura de la obra" (pág. 36). Con lo que atañe al artista, su labor queda completamente "desmitificada", para dar lugar a su función social como miembro activo del contexto y como ese actor que trabaja colectivamente, permitiéndose la posibilidad de construir con el otro. En definitiva, la reciprocidad entre artista y espectador se torna como elemento fundante de lo comunitario y lo público.

La relación entre arte contextual, arte público y arte comunitario, es clara: buscan crear otros vínculos entre el espectador, la obra y el artista, pensando siempre en la realidad en que se encuentran. Así, la noción que hasta ahora se puede identificar de las PAC, consiste en definirlas como una construcción que se desarrolla en el aquí y el ahora y se elabora con el otro, desde sus intereses, particularidades y diferencias. Por ahora se puede decir que las PAC son aquellas que se preocupan por generar, en contextos específicos, experiencias colaborativas y democráticas alrededor del arte, integrando el medio local y a los actores que se encuentran allí; además, apuntan a una reflexión ante lo social y la realidad que da cuenta de la participación directa y activa del espectador, de su capacidad creadora y colectiva, preocupándose por el otro, por lo intersubjetivo y por su realidad inmediata.

Para contrastar la reflexión teórica que se ha expuesto, a continuación se presenta la PAC "Una Mirada al Ayer" desarrollada en el municipio de Guatavita, Cundinamarca, junto con diez mujeres de esta comunidad. Esto para contribuir un poco a la discusión del concepto de las PAC.

\section{“Una mirada al ayer”: Una PAC con diez mujeres del municipio de Guatavita}

El municipio de Guatavita es reconocido por ser un sitio turístico importante de la sabana de Bogotá; la mayor parte de personas la reconocen por su "tranquilidad" y su "bonita" arquitectura, o bien, por la laguna y la Leyenda de El Dorado. Sin embargo, lo que interesó desde el desarrollo de una PAC fue evidenciar aquello que ocurre detrás de esta imagen, un tanto estereotipada, construida desde el turismo, la publicidad, los discursos oficiales y algunos lugares comunes que excluyen la complejidad social de la memoria, sus significados, lo subjetivo y las dinámicas de la comunidad construidas en torno a ello.

Guatavita como cualquier otro pueblo del altiplano cundiboyacense, se caracteriza por su clima frío; la gran influencia de la institucionalidad religiosa; lo tradicional y lo campesino, pero que por su relativa cercanía a Bogotá, está fuertemente afectado por lo urbano. Por ser un pueblo comparativamente pequeño, tiene unas particularidades que definen la cotidianidad, las relaciones sociales entre vecinos y, en general, la configuración colectiva del pueblo. 
Por otra parte, debe hablarse de un hecho fundamental desde el cual se "hilan" los relatos y recuerdos individuales de la comunidad, además de definir la historia misma de la población y de determinar fuertemente el contexto: esto es, el traslado espacial del pueblo. En el año de 1967, debido a la construcción del embalse del Tominé, los habitantes tuvieron que situarse en otro lugar, una nueva construcción ("Pueblo Nuevo") que reemplazara su "Pueblo Viejo" y que conllevó a un proceso de cambios y transformaciones sociales, económicas, espaciales, etc. Por ello, este acontecimiento estructura un espacio-tiempo concreto

En este contexto, se propuso una PAC: "Una mirada al ayer", que diese cuenta de cómo cada una de las vivencias, experiencias y recuerdos de diez mujeres de la comunidad, se enlazaban para construir una versión de esa memoria colectiva ${ }^{3}$.

Para convocar a estas personas, se hizo uso de una serie de criterios: que fueran mujeres, pues la comunidad es estrictamente matriarcal desde la crianza, la educación de los hijos, la organización de la memoria familiar (fechas, álbumes familiares, etc.); muy relacionado con lo anterior, que fueran madres, abuelas, bisabuelas, tías o "hijas cuidadoras" de sus padres; que se consideraran católicas, ya que la religión define gran parte de la memoria colectiva desde las prácticas y discursos que circulan y definen el imaginario (Castoriadis, 2007); mayores de 50 años, ya que vivenciaron el traslado del pueblo; natales de Guatavita y residentes del casco urbano; y finalmente, que ocuparan algún lugar relevante dentro de la memoria del pueblo, ya sea por su ocupación, edad, estatus, etc.

De este modo, en el grupo participó Doña Lolita: con ochenta y siete años de edad. Todo el pueblo la recuerda por ser la madre del primer niño nacido en Guatavita la Nueva; ella es madre, abuela y bisabuela. La Señorita Lucila, fue una de las modistas más destacadas del pueblo y enseñó a muchas mujeres este oficio, crió a varias de sus sobrinas. Una de ellas es Fanny, que también hizo parte del grupo, actualmente vive con su madre y atiende un restaurante. La profesora Luz Bery, fue docente del área de español del colegio del pueblo por más de 30 años, educó a varias generaciones y cuidó a sus padres. La profe Beatriz, también pensionada como maestra de primaria de la escuela del pueblo, es madre y abuela. Doña Clara, madre y abuela, elabora muchos objetos desde los bordados y tejidos, vivió por varios años en Bogotá y regresó hace un tiempo a Guatavita. Omaira, la más joven del grupo, es madre de un hijo y se dedica a la docencia en un colegio del distrito, actualmente reside en la ciudad, pero visita a su mamá cada fin de semana para ayudarle en su negocio de artesanías.

\footnotetext{
${ }^{3}$ Optando algunos postulados de autores como Maurice Halbwachs (2004) y Félix Vásquez (2001), por "memoria colectiva" se entiende aquel proceso de construcción social, cargado de significados compartidos, que dota de sentido al mundo y en el que se hace una constante e inacabada reinterpretación del pasado. Desde esta óptica, la memoria es móvil, cambiante y parte del encuentro social, las prácticas sociales y los usos del lenguaje en un contexto y momento histórico determinado; a su vez, está definida por una serie de marcos o estructuras sociales (el tiempo y el espacio) y dialoga con la memoria individual, en tanto esta última es una versión de lo colectivo. La re-construcción del pasado atiende a las necesidades en el presente y se expande al futuro para garantiza la continuidad social.
}

La práctica de tejer se evidencia también gracias a Doña Yolanda, como madre y abuela, se dedica principalmente a las labores del hogar, entregada a su casa, a sus hijos y a su esposo, quien fue director de la Caja Agraria por muchos años en el Pueblo Antiguo y en el Nuevo. Doña Leonor es madre de uno de los ex-alcaldes del pueblo, también es abuela y muy entregada a su hogar. Finalmente, Doña Martha, madre y abuela, en ocasiones hace tortas y otros productos de pastelería, oficio que aprendió de su madre, es ama de casa y actualmente guarda el luto por su esposo. A continuación se hace alusión a algunos aspectos que vale la pena precisar a propósito del desarrollo de esta PAC.

\section{¿En qué consistió la obra? ¿Qué se hizo?}

La Memoria Familiar, fue el eje trasversal de la experiencia, desde allí lo que se buscaba era lograr re-construir la Memoria Colectiva de los guatavas (personas originarias de Guatavita). Partiendo de las historias de vida de un grupo de diez mujeres de la comunidad, quienes contaron lo que más recordaban de su vida y de su familia. El relato como fuente principal de información, fue ayudado por una serie de "dispositivos contenedores de memoria" (escritos, mapeos, etc.) que encaminaban estas narraciones.

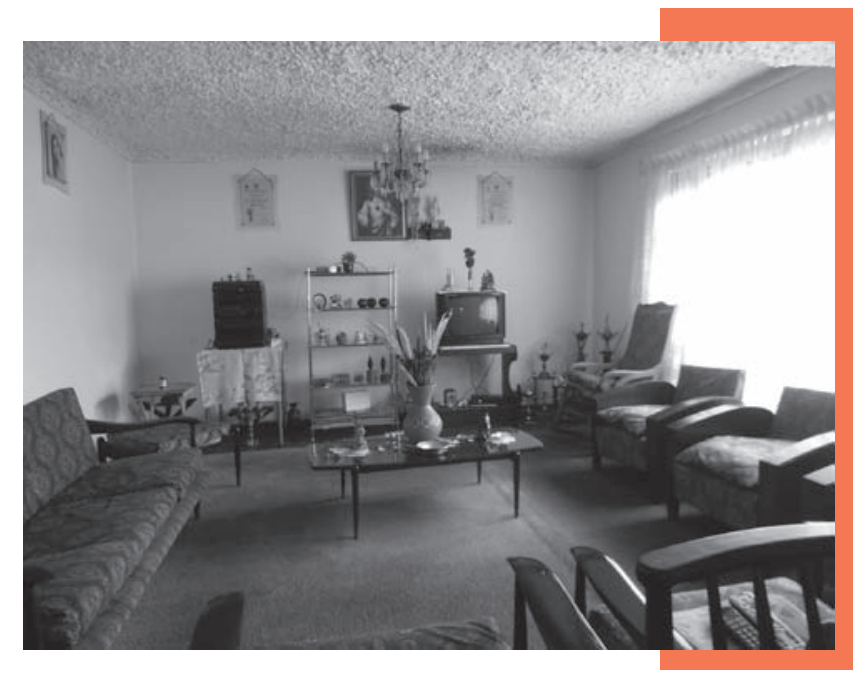

Imagen 1: Sala de Fanny

La imagen de Viajero que se optó para establecer una serie de visitas a estas mujeres, tuvo por objeto evidenciar la relación directa entre el contexto y el artista-mediador, miembro de la comunidad y natal de Guatavita, proponente de la PAC. Así, se hizo una serie de recorridos hasta las casas de algunas habitantes del casco urbano del municipio. Cada uno de estos viajes, rutas, trayectos, tuvo como finalidad realizar una visita a estas personas y crear encuentros para recordar. Cada vez que este visitante llegaba periódicamente a la casa, surgía una serie de espacios para relatar recuerdos familiares. La sala del hogar, es el lugar entendido como escenario donde cotidianamente ocurren los encuentros entre los vecinos, alrededor de un café, se convierte en el espacio donde este visitante "irrumpía" en lo doméstico. Poco a poco, la memoria de cada señora fue "hilándose", creando una serie de conexiones que desembocaron en la necesidad del encuentro colectivo. 


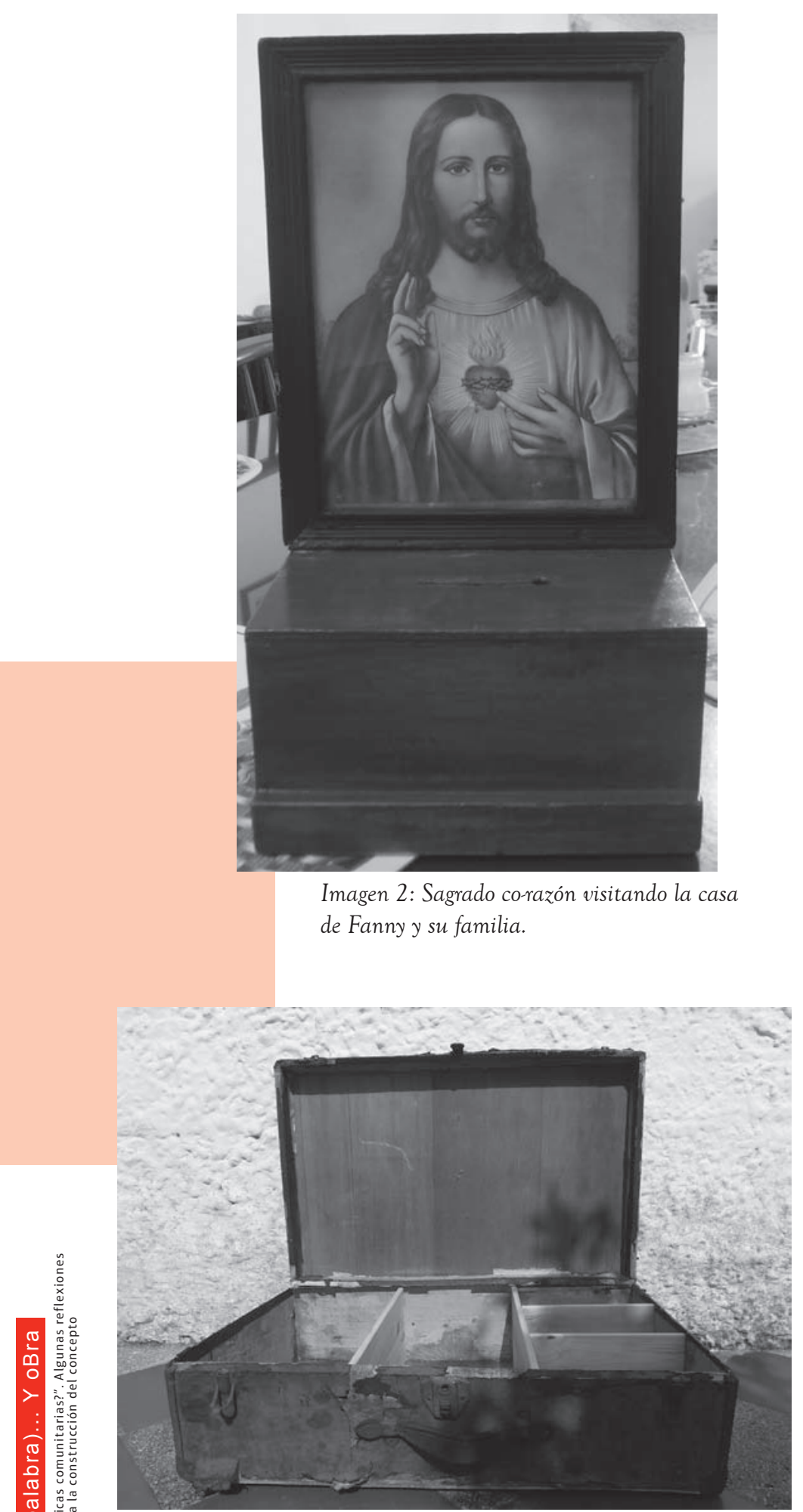

Imagen 3: Maleta contenedora de la memoria.
Cada familia representada en su matrona de casa, constituyó algo así como un nodo, que se articulaba con los otros para formar un sistema más complejo. Cada uno de estos puntos empezó a contener "nodos internos", pues en cada ejercicio propuesto se involucró directa o indirectamente a toda la familia. En los diálogos que emergían interna y externamente, fue donde apareció un "nuevo relato" que daba cuenta de la memoria colectiva en un entramado de relaciones que se fue tejiendo poco a poco.

Las visitas tuvieron una duración de aproximadamente cuatro meses, fueron divididas en seis encuentros con cada mujer. Esta primera parte de la práctica artística desembocó a una segunda etapa, que intentaba trasladar lo construido individualmente a lo colectivo, esto desde el desarrollo de cuatro encuentros grupales en el segundo semestre de 2012.

\section{¿Desde dónde?}

Pensando en un dispositivo para acumular los recuerdos encontrados durante los recorridos, se tomó como referente una tradición religiosa propia del pueblo: una caja con la imagen de la Virgen María o del Sagrado Corazón, viaja "de casa en casa" por todo Guatavita con la intención de recoger el diezmo y destinarlo a un determinado fin cuando se llene, el cajón-alcancía realiza una serie de recorridos acordados entre las personas.

\section{El Dispositivo}

Tomando la figura del viajero y la caja con la imagen del santo(a) como referentes se pensó en encontrar un contenedor de la memoria. Un objeto-dispositivo que se materializó en una maleta-pertenencia del abuelo y el pasado familiar del artista- usada para recorrer y para contener la memoria colectiva. Don Juvenal, un señor que aprendió el oficio de carpintería con su patrón, fue quien arregló cuidadosamente la maleta contenedora que se convirtió en producto del proceso artístico y en testimonio de lo acontecido: los relatos grabados en audio y el desarrollo de los ejercicios pensados como dispositivos para cada visita.

\section{Los Encuentros}

Con relación al proceso de convocatoria de las mujeres participantes, se hicieron algunos desplazamientos a cada una sus casas para concretarlas "voz a voz" y luego programar las visitas. Durante el desarrollo década uno de los seis encuentros, la atención se centraba en una de las etapas de la vida (la infancia, la juventud, la adultez, la vejez...) para abordarla desde el recuerdo, el relato de vida y un dispositivo detonante de memoria que facilitara las narraciones desde una serie de preguntas articuladoras y de carácter abierto. De este modo, los encuentros se llevaron a cabo de la siguiente forma: 


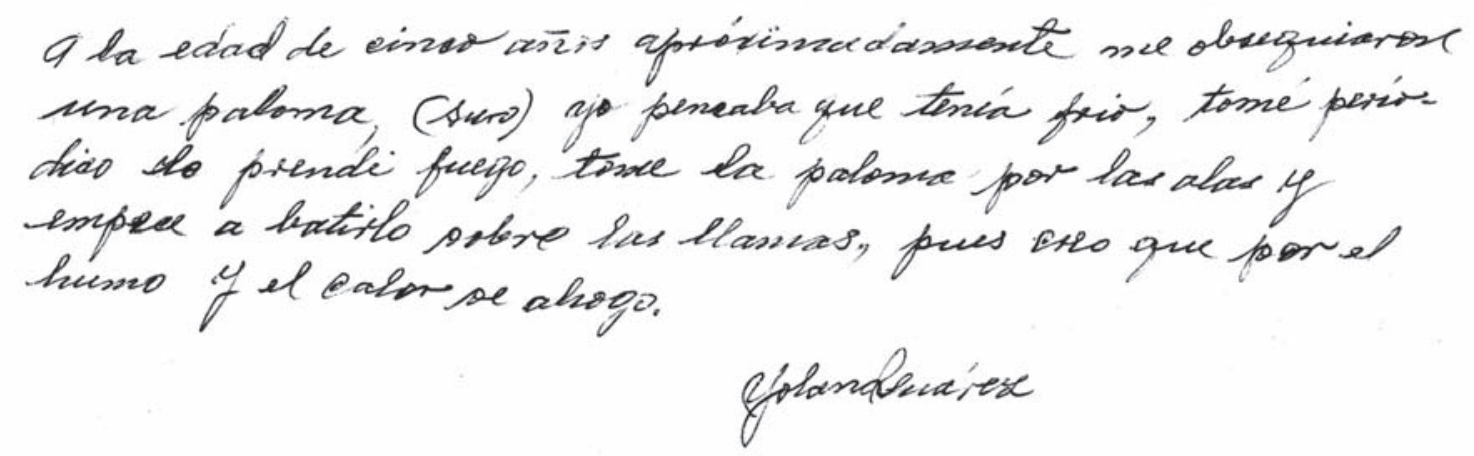

Imagen 4: Texto de doña Yolanda

Vista 1: La Infancia (abril 16 al 22)

El objetivo esta vez, consistía en enfatizar la memoria individual, y por consiguiente, los primeros años de vida de estas mujeres: la configuración de la familia paterna, la relación con los abuelos, las prácticas religiosas, el Pueblo Antiguo, la escuela, etc. Así, estas fueron las preguntas que sirvieron para hacer emerger el relato: ¿qué es lo que más recuerda de su infancia?; ¿cuáles eran la celebraciones, festividades, eventos... que se hacían en esa época?; ¿qué es lo que más recuerda de sus padres?; ¿cómo era la relación con sus hermanos?; ¿cómo era su casa?; ¿quiénes eran sus vecinos?; ¿quiénes eran sus amigos?; ¿cuál fue su primer juguete?; ¿a qué jugaban?; ¿cómo era la escuela?; entre otras. El desarrollo de un "ejercicio de creación" que ayudara al relato, se centró en la escritura de un recuerdo de la infancia que se considerara relevante.

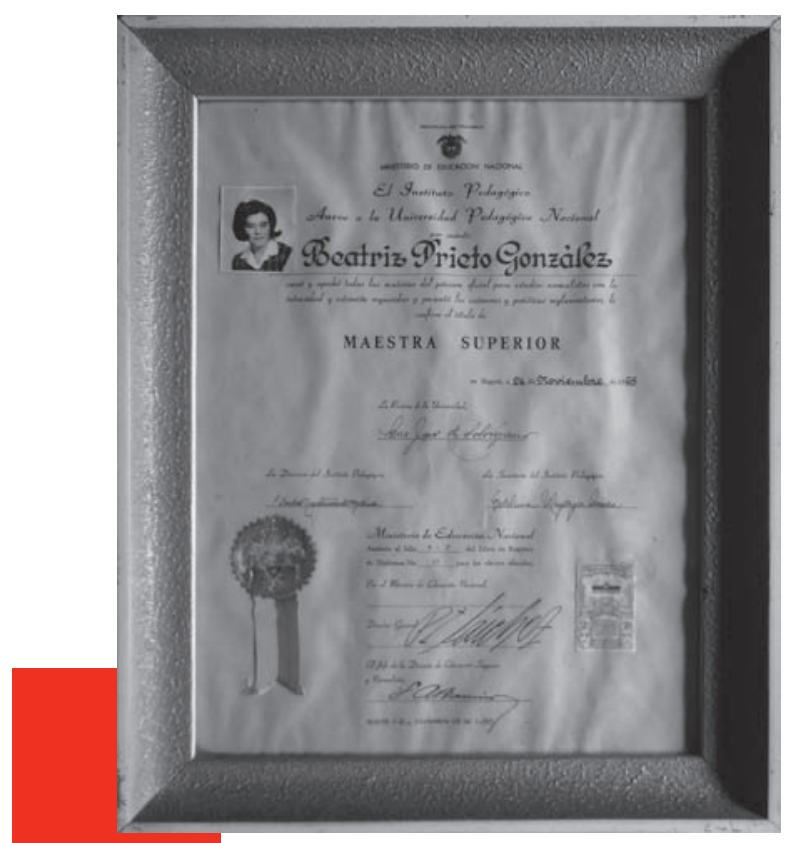

Imagen 5: Diploma de la profe Beatriz
Vista 2: La Juventud (abril 23 a mayo 06)

El segundo encuentro buscaba hacer una recopilación de los recuerdos entorno a los años de juventud de cada una de las mujeres visitadas. El dispositivo que se empleó como recurso fue la selección de un objeto de la casa que se relacionara directamente con la juventud; así las preguntas que precedían el ejercicio fueron: ¿qué recuerdo le evoca ese elemento?; ¿cómo trascurrió su juventud?; ;cómo fue su educación?; ¿cuál fue su primer trabajo?; iqué amigos recuerda?; ¡cómo eran los noviazgos de la época?; ¿cuál fue su primer novio? Para el caso de las mujeres casadas se pensó en preguntas como: ¿cómo conoció a su esposo?; ¡cómo fue su matrimonio? 


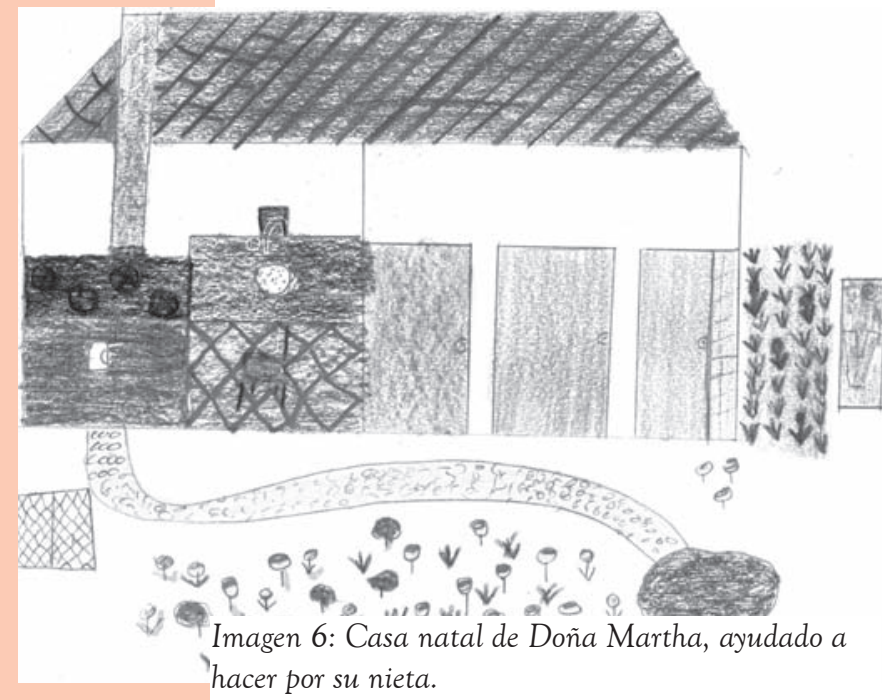

Vista 3: El traslado (mayo 07 al 20)

Con la intención de referirse a los espacios, concretamente a Guatavita la Vieja, y a las transformaciones sufridas en el traslado del pueblo, como dispositivos de apoyo; cada mujer realizó un dibujo de su casa natal, que luego ubicaba en un mapa del Pueblo Viejo, junto con los sitios más representativos de allí. Por ello, se empleó una fotografía panorámica y un mapa a gran formato que se fue completando por cada señora y en cada visita. Algunas preguntas articuladoras para el relato fueron estas: ¿qué lugares eran los más relevantes del pueblo?; ¿cómo fue el traslado?; ¿cómo fue el proceso de desalojo?; ¿qué la marcó del traslado?; ¿cómo marcó a su familia?; ¿qué cambios hubo? (espaciales, personales, familiares, económicos...); ¿qué diferencias y semejanzas hay entre la vida del Pueblo Viejo y el Nuevo?; etc.

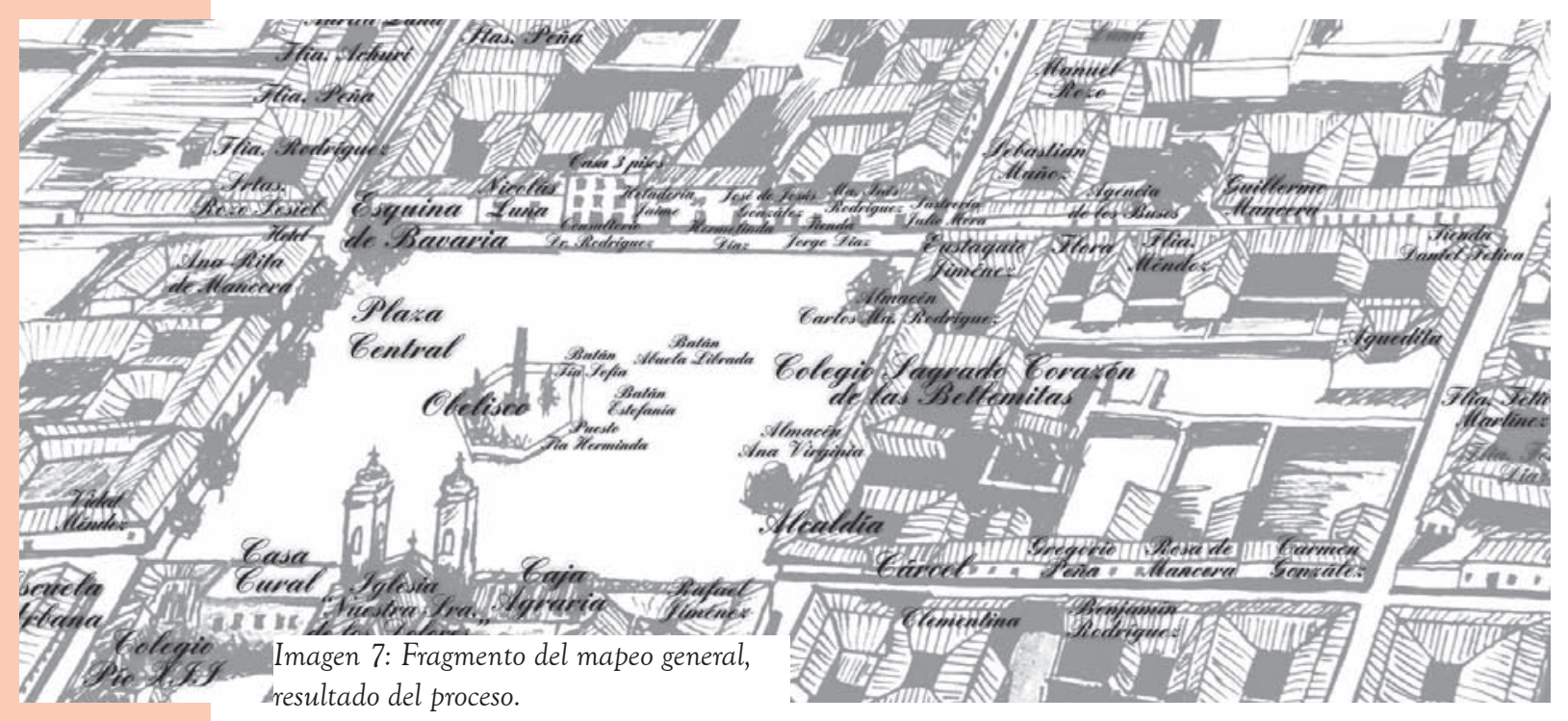

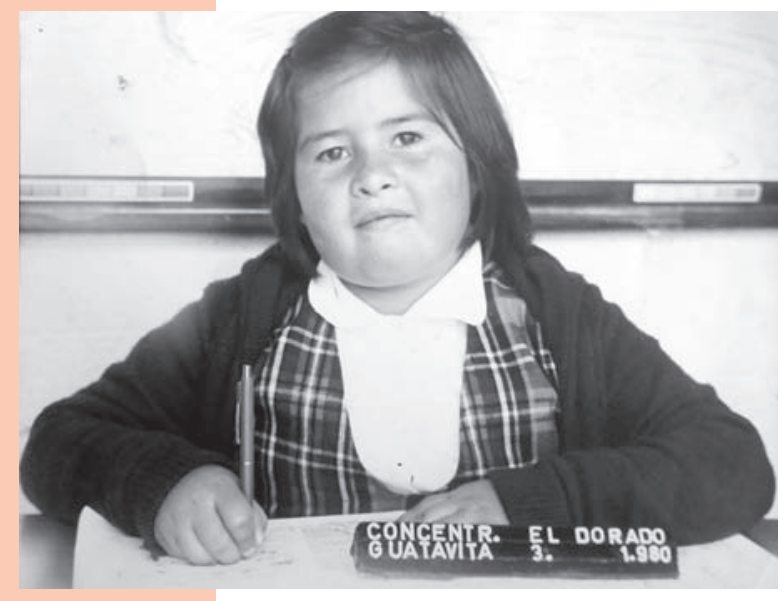

Imagen 8: Fotografía del álbum familiar de doña Martha
Vista 4: La adultez: vida de casada - vida soltera (mayo 21 a junio 03)

Para intentar evidenciar con mayor claridad las fechas, conmemoraciones y prácticas dentro de la memoria familiar, apareció como dispositivo la revisión de álbumes familiares; para que, desde el relato, cada señora describiera detalladamente cada fotografía: lugares, eventos, la vida de los hijos, etc. Las preguntas empleadas fueron las siguientes: ¿cómo trascurrió su adultez?; ¿cómo fueron sus trabajos?; ¿cuáles han sido los momentos más importantes de su edad adulta?; para las casadas: iqué diferencias hay entre su vida de soltera y de casada?; ¿cómo ha sido su matrimonio?; ¿cómo fue su primer embarazo?; ¿cómo fue la infancia de sus hijos?; ¿cuál fue su primer hijo?; ¿cuál fue su primer nieto?; en el caso de las solteras: ¿cómo fue o ha sido el cuidado de sus padres?; ;por qué decidió cuidarlos?; ¡cómo es la relación con sus sobrinos? 


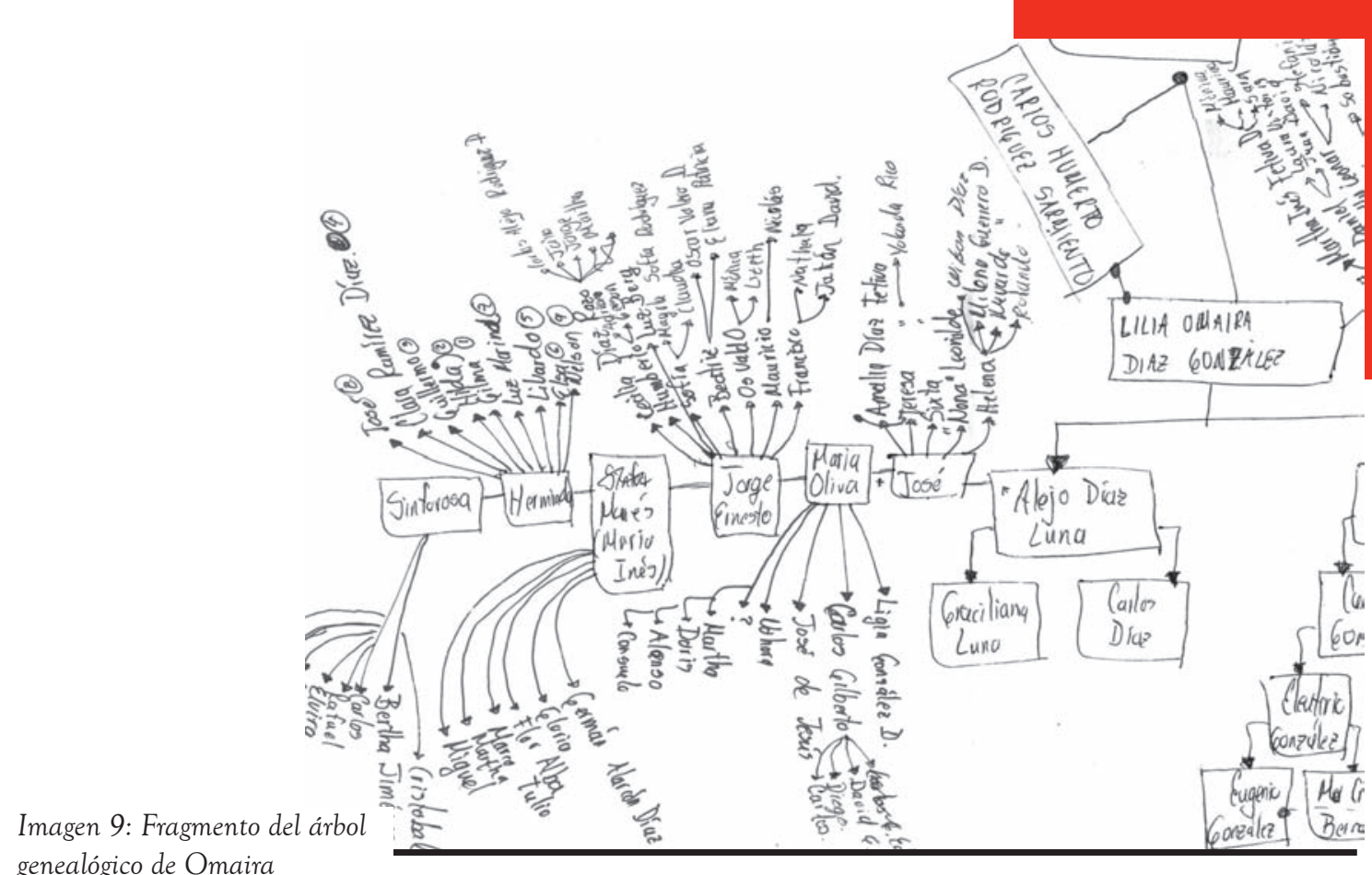
genealógico de Omaira

Vista 5: El presente-la vejez (junio 04 al 17)

La finalidad de esta visita consistía en armar, con cada señora, su árbol genealógico desde una lista de sus familiares elaborada con anterioridad. Luego, con los árboles individuales se buscó construir un árbol general en cual se hallaban las uniones entre las familias; esto para comprender la configuración de la familia en la actualidad. Preguntas como: ¿cómo ve a su familia hoy en día?; ¿qué tan unida es?; ¿qué piensa de las nuevas generaciones?; ¿cómo es la vida de sus hijos en la actualidad?; ¿quiénes son sus nietos?; ¿qué hacen?; entre otras, estructuraron el encuentro.

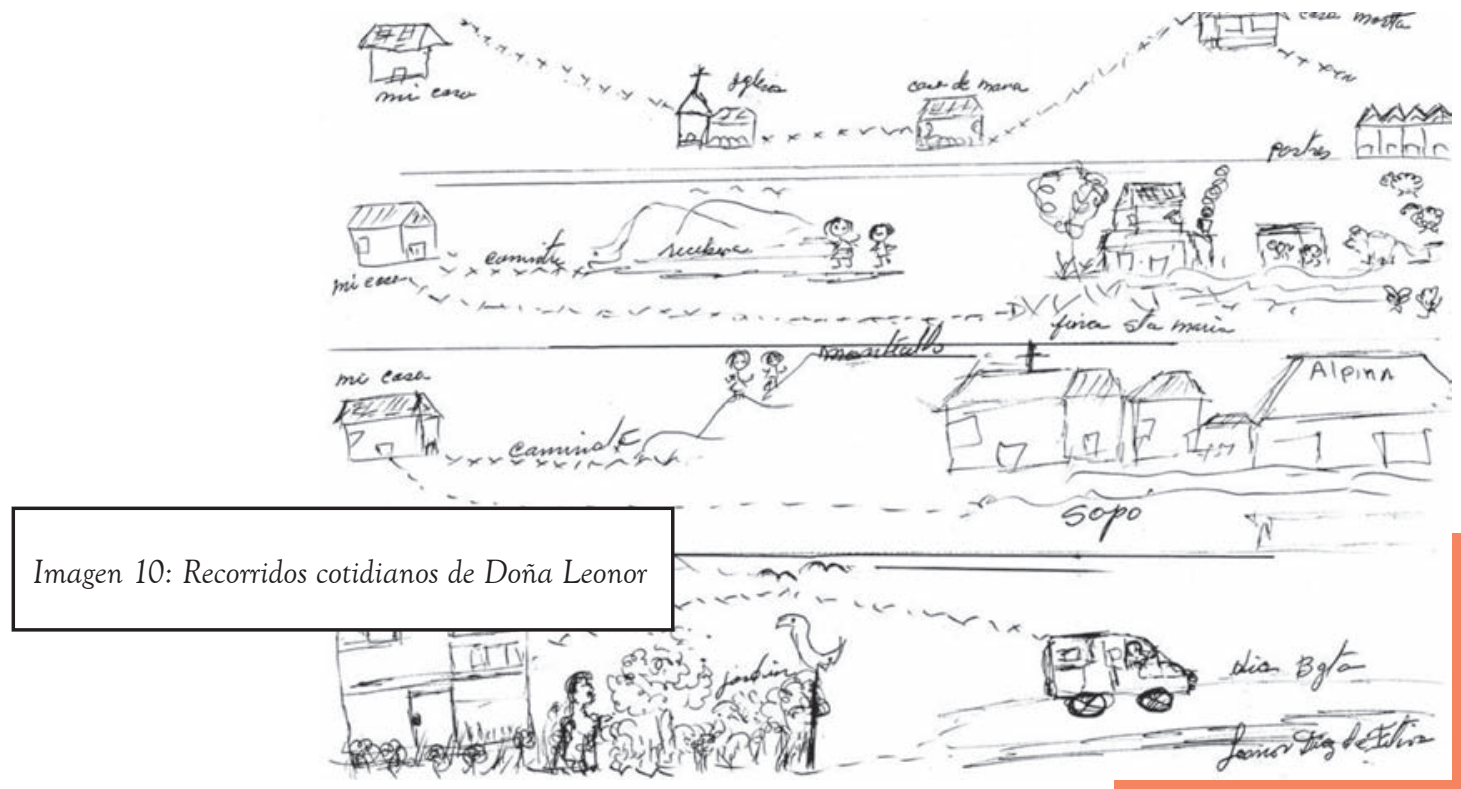

Vista 6: El presente- Pueblo Nuevo (junio 18 al 24)

Evidenciando la relación actual de estas señoras con los espacios que habitan y con el Pueblo Nuevo, se pidió a cada una que dibujara o escribiera sus recorridos cotidianos; luego invitarla a que indicara su lugar predilecto de la casa y lograr una fotografía, preguntar el por qué de la elección, por qué ese y no otro, qué significado tiene ese lugar, qué significa su casa, etc.

Además, se hizo un cierre individual de esta parte del proceso, donde se quería evaluar lo ocurrido alrededor de las siguientes preguntas: ¿cómo le ha parecido el proceso hasta ahora?; ¿cuál fue el ejercicio que más le gustó, cuál el menos?; ¿ha aprendido algo?, ¿qué?; ¿le parece importante lo desarrollado hasta el momento?, ¿por qué? 
Homenaje a la señorita Lucila (mayo 12)

Una de las mujeres convocadas fue la Señorita Lucila, con ochenta y tres años y avanzados problemas de salud debido a su vejez. Su sobrina y ella misma, con el apoyo de la enfermera que la cuidó, accedieron a participar en el proceso. A causa de estos problemas de salud, no se pudieron realizar cada uno de los ejercicios que inicialmente se propusieron para todas las señoras, por esta razón se pensó en otro tipo de dispositivo para reconstruir su memoria. Tomado en cuenta que fue una de las modistas más destacadas del pueblo y que enseñó a muchas mujeres este oficio, lo desarrollado con ella todo el tiempo giró en torno a su labor para tratar de evidenciar su lugar dentro de la memoria colectiva de las mujeres de Guatavita.

Por ello se llevó a cabo un homenaje en el que se logró reunir en la sala de su casa a muchas de sus alumnas de modistería y al resto de las mujeres que hacían parte del desarrollo de la obra, que finalmente se reconocieron como sus clientas de costura. Dos días después de su homenaje y reconocimiento, la Señorita Lucila falleció. El registro en audio de su entierro y lo ocurrido el día quinto de su novenario, enlazado con lo sucedido en la misa de nueve noches, también hizo parte del material plástico para la obra.

\section{Cierre colectivo (julio 21)}

Como objetivo central de este primer cierre de la PAC, se buscó emplear el encuentro como dispositivo. La relación individual-colectivo se hizo indispensable para socializar lo que hasta el momento se había desarrollado. En un café-galería situado cerca a la casa cural del pueblo, el grupo de señoras se reunió para trasladar lo construido en la sala de sus casas y compartirlo con las demás, empezando a entender la importancia de encontrarse.

La exposición de la maleta con parte del material elaborado; la construcción de una presentación con algunas de las imágenes y de los relatos obtenidos, fueron proyectados en la pared; y el desarrollo de una "graduación", donde a cada mujer se le entregó un diploma como muestra de agradecimiento y reconocimiento dentro del proceso; fueron otros dispositivos que hicieron parte del encuentro.

Desde esta necesidad de encontrarse, se decidió llevar a cabo una segunda etapa de creación concentrada en las reuniones grupales. Vale la pena mencionar a grandes rasgos, los desarrollos y logros dentro de este proceso.

Imágenes 12, 13 y 14: Exposición de la maleta y parte del proceso; cierre colectivo, primera etapa de la PAC.

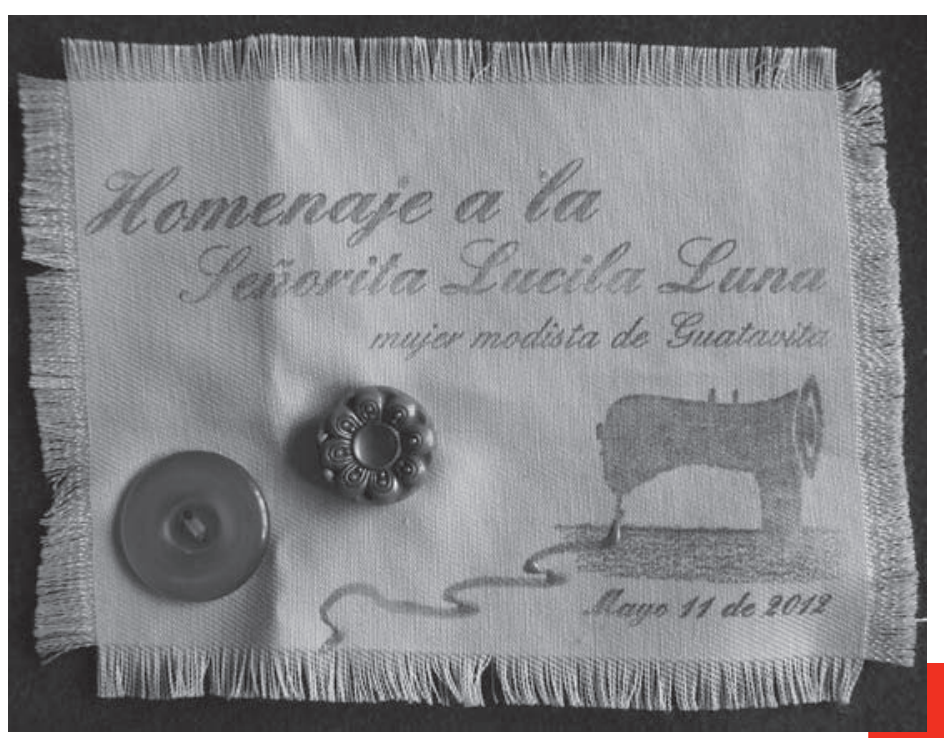

Imagen 11: Recordatorio Homenaje Srta. Lucila.
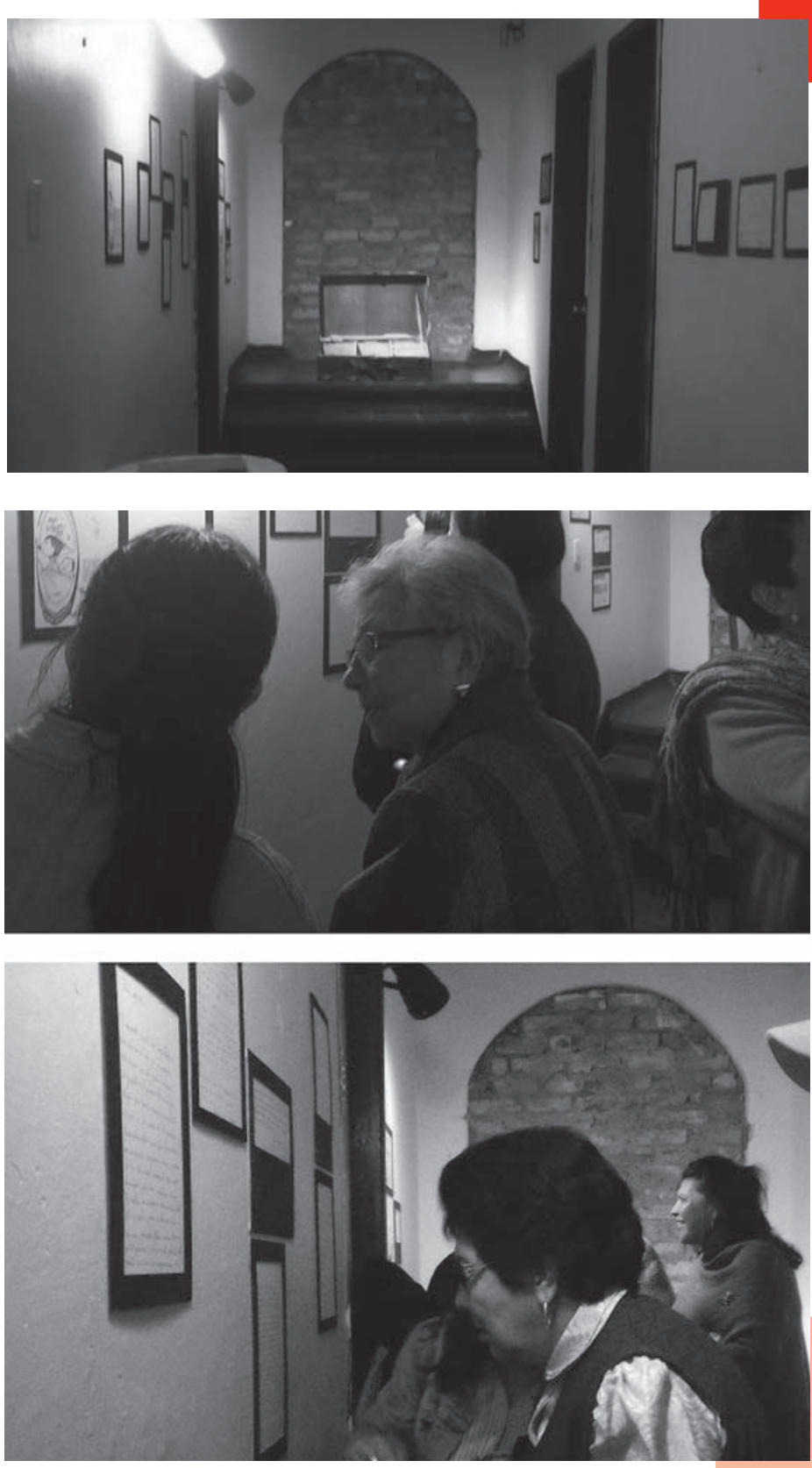


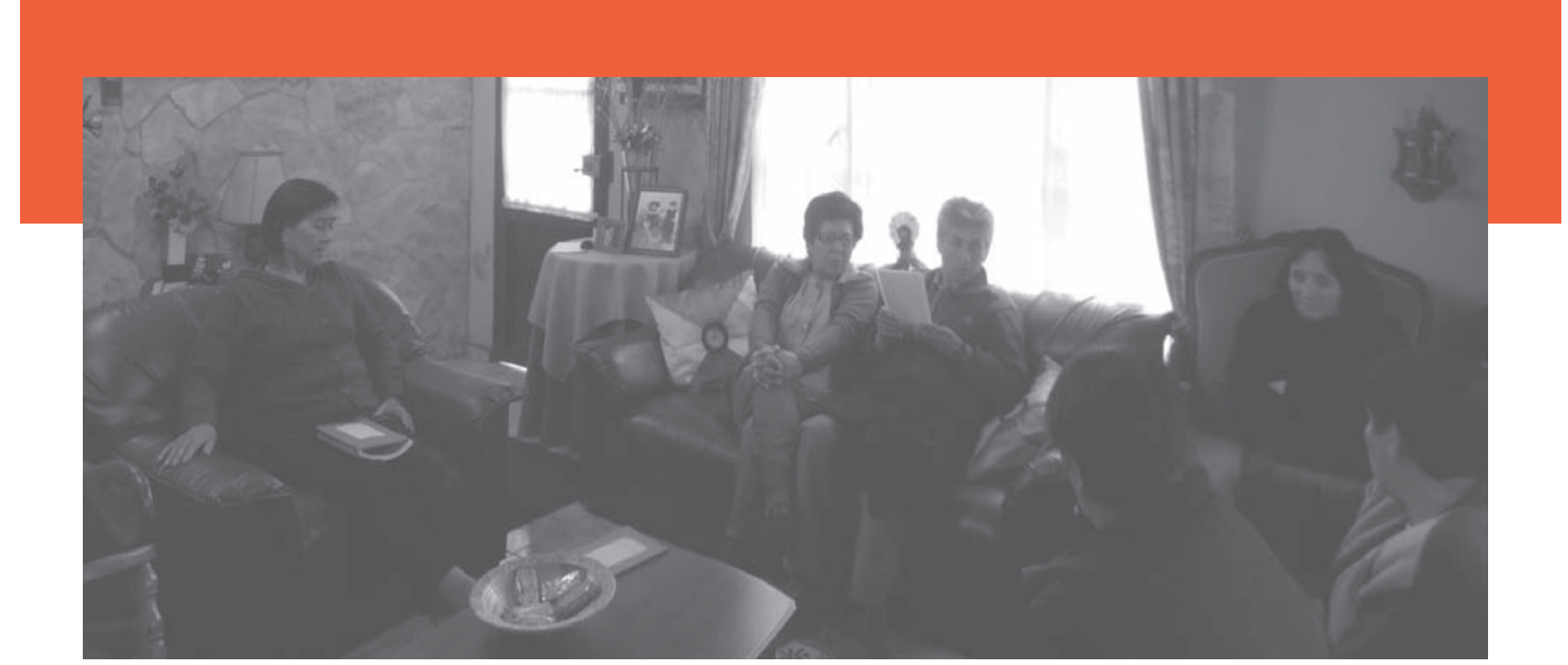

\section{Segunda etapa de la PAC}

Para seguir con el proceso de articulación entre lo individual y la construcción colectiva, esta segunda etapa de la PAC, buscaba llevar a cabo cuatro encuentros con todas las mujeres vinculadas al trabajo, incluyendo a varias de las hijas que ya se consideraban elemento fundamental de la obra. La sala de las casas de algunas sirvió como escenario para reunirse.

La socialización grupal del ejercicio de creación personal basado en la escritura de su autobiografía, definió la metodología de todos estos encuentros. Al iniciar, cada mujer recibió un sobre con papel y las siguientes preguntas anexas: "¿Qué es lo que más recuerda de su infancia?, ¿cómo era su casa de Pueblo Viejo?, ¿cómo fue su juventud?, ¿cómo transcurrió su adultez?, ¿cómo ve su vida hoy en día?, ¿qué significa su familia?, ¿qué significa ser mamá, abuela o tía?, ¿cuál ha sido el momento más feliz de su vida?. Además se presentó la siguiente indicación: Las siguientes 100 páginas son un espacio para responder a todas estas preguntas. Contar la historia de su vida: consignar recuerdos, anécdotas y experiencias en el transcurrir de su existencia, es el único objetivo de este ejercicio. Dibujos, Escritos, Fotos, Recortes... también se vale la ayuda de la familia, de los hijos o los nietos. La invitación es para que hablemos de nosotros mismos, de nuestras familias, de nuestro pueblo, de nuestra memoria... la invitación es para que sencillamente demos 'Una mirada al ayer'”.

Al finalizar los encuentros colectivos y a manera de exposición, la obra fue socializada con todos los familiares de las señoras y con la comunidad en general, esto para dar por terminada la PAC.

\section{El lugar de la PAC en la re-significación}

¿Cuál fue el lugar que la PAC ocupó durante el proceso de creación descrito anteriormente?, ¿cuál es la relevancia para el contexto de cada uno de los dispositivos desarrollados por cada señora durante las visitas y encuentros?, ¿cómo no caer en la instrumentalización del arte? Pues bien, sin la intención de resolver completamente estas preguntas, lo que se intenta elaborar es una aproximación a la pertinencia que pueda tener para el contexto y la comunidad "Una Mirada al Ayer" en su posibilidad de re-significación de memoria de los actores. Las reflexiones que vienen se presentan como una "insinuación" para el apartado siguiente relacionado con algunas construcciones en torno al concepto de PAC.

Un primer elemento a destacar es que la mirada sensible del entorno que desde la labor del artista-mediador, todo el tiempo se hizo presente. Si bien, es la práctica artística en su inserción con lo real donde cobra sentido, lo que Ardenne (2006) menciona a propósito del arte contextual: la manera como el artista hace dialogar perfectamente la obra y la realidad en que se encuentra. Por su parte, trasladar la concepción de lugar más allá de su comprensión puramente física para hablar de la contextualidad de ese espacio, teniendo en cuenta sus significados sociales, las problemáticas que circulan allí, la memoria misma, etc. no es otra cosa que evidenciar lo que Paloma Blanco (2001) menciona a propósito del arte público como un "arte del lugar". Allí "el artista, a través de su trabajo con la comunidad, puede ayudar a despertar en el paisaje social su sentido latente de lugar" (pág. 32). Esta inserción en el contexto de la obra, del artista y de los actores-creadores, fue el punto de partida para poder establecer conexiones entre la realidad particular de las diez señoras de Guatavita y el desarrollo de la PAC. 
"Sabe que todo lo que usted me estuvo averiguando mi vida, todo me gustó, porque como que lo hace a uno recordar y como que se siente uno en esa época, bonito, es muy bonito, ¿uno cuándo habla de su familia?, icon nadie!" Doña Lolita.

"Pues me enseñó a dibujar (risas), me enseñó a dibujar otra vez y a mirar a ver cómo es y pues a mi si me gustó". Doña Martha.

"A mi me pareció chévere porque uno empieza a recordar, a recordar realmente su vida". Omaira.

"Son como experiencias, como cosas que uno por la mente nunca le pasaron, que alguien viniera a estar con uno, a tener uno charlas". Doña Yolanda.

"Para uno como siempre es lo más bonito regresar a la época de la infancia y como la época de la adolescencia, la entrada a la juventud, a mi se me hace que eso, siempre para uno es muy bonito recordar y contar lo que uno hacía, cómo era esa época de infancia y de la adolescencia, entrada la juventud". Profe Luz Bery.

"iAh no, bonito! Porque eso es una cosa que también le ayuda a uno como a sentir alegría que es útil para hacer todas estas cosas, para recordar cosas bonitas, si”.

Doña Leonor.
Si se toma en cuenta que la finalidad última de la educación artística es permitir al ser humano un conocimiento del mundo, haciendo conciencia de su vida y re-significando su existencia, pues el sujeto es reafirmado desde el arte en diálogo con otros y su realidad inmediata, se puede ver que la pertinencia de la PAC cobra mucho más sentido desde sus posibilidades educativas; así lo afirma Eisner (1998) cuando justifica aquello que le es propio a la experiencia del arte: "el valor principal de las artes en la educación reside en que, al proporcionar un conocimiento del mundo, hace una aportación única a la experiencia individual. Las artes (...) remiten a un aspecto de conciencia humana que ningún otro campo aborda" (p. 9).

En este mismo sentido, se hace pertinente hablar de una confluencia entre el arte y la pedagogía, basada en la construcción, realización y reflexión de una serie de acciones intencionadas, con sentido y pertinentes desde cada uno de los "dispositivos contenedores de memoria” que se propusieron (la maleta, los escritos, los encuentros, etc.), que permitían emerger el elemento de la "conciencia humana" basado en la elaboración de conocimientos que parten de la experiencia y el saber popular, y que son validados en el campo artístico. En la medida en que el grupo de mujeres se pensaba a sí mismas desde sus propias comprensiones sobre el mundo y reconocía sus prácticas cotidianas como fuente para la creación, aparecía ese diálogo entre el arte y la pedagogía, el aprender y el enseñar.

Por ello para hablar del proceso de re-significación de la memoria en el caso de cada una de las señoras es vital, la experiencia artística y estética permiten ver lo cotidiano desde otra óptica, aquí yace el significado de la obra que trasciende lo material. Para cada una de las diez mujeres, tomar distancia de su propia memoria y hablar de ellas mismas, escuchar a la otra, encontrarse con las vecinas y hallar puntos en común de sus historias de vida, fueron algunas de las estrategias que contribuyeron a este proceso.

Pero, ¿qué es lo que en realidad se aprende en una PAC? No es concretamente una técnica artística ni a cómo hacer un "buen arte" que se materializa en una evidencia del proceso (en este caso la maleta). Las PAC son una serie de redes complejas de relaciones que apuntan a la reafirmación de la subjetividad de los actores, los cuales toman como material artístico sus vidas, lo cotidiano, lo sencillo, lo inmediato o su memoria. Esto constituye la esencia real de la obra y los aprendizajes que se construyen allí, que no es otra cosa más que la re-significación de la existencia humana.

Por otra parte, basándose en la re-significación subjetiva, se tiene que el carácter intersubjetivo, en este caso, supera la re-afirmación puramente individual; articulándose con el carácter social desde el cual se
"Entonces es mucha cosa que aprendí: aprendi a conocer mi familia, y eso que no profundizamos más ¿no? Pero aprendi mucho a conocer, verdad, a mi familia".

Profe Beatriz.

"Hay cosas que uno ya ni se recordaba y me he puesto a recordar muchas cosas, (...) por ejemplo, uno por allá ya no se acordaba y con este taller pues ha estado bonito por lo que entonces he recordado cosas. Muchas cosas que de verdad uno no, (...) y ahora pues se pone uno a pensar, y a analizar, y recuerda cositas que estaban por allá como perdidas”. Doña Clara.

"A mi me llama la atención que todas esas preguntas que me ha hecho a mi, las que han tenido relación con el pueblo y eso, yo sí quisiera saber qué contestaron las otras personas, como que me llama la atención eso: 'y qué contestaría Yolanda, y qué contestaría Leonor Fetiva y qué contestaría... ¿coincidiríamos, no coincidiriamos?' (risas), entonces todo eso me ha llamado la atención”. Profe Luz Bery.

"Decía Doña Cecilia, la esposa del mayor Rodri-guez: Guatavita es una sola familia, porque todos, todos son de una sola familia, decía ella”. Doña Leonor. 
está comprendiendo la memoria, como una construcción colectiva basada en el encuentro y el uso del lenguaje (Vázquez, 2001), la re-significación como grupo humano, como mujeres y como guatavas, pone en evidencia el diálogo individual y colectivo que también le compete a la experiencia del arte. A propósito de esto Bourriaud (2006) habla de un "arte que parte de la intersubjetividad, y tiene por tema central el 'estarjunto', (...) la elaboración colectiva del sentido” (p. 14); este tipo de experiencias que parten del encuentro y el diálogo, son característica central del arte relacional. Más allá de entenderse como una relación directa entre el artista y sus espectadores, apunta más bien a una construcción de significados compartidos entre todos los participantes inmersos en una PAC. Esto mismo lo asegura Ardenne cuando se refiere al arte participativo: "la obra 'otrista' tiene por vocación suscitar un 'estar juntos'. A la espera de una mayor solidaridad social (al menos localmente), apostando por la posibilidad de una intersubjetividad realizada (al menos de manera pasajera), la obra de arte participativa se constituye como un agente activo de la democracia vivida, de la que es, probablemente, el más significativo hijo simbólico" (Ibíd.).

Todo lo anterior conlleva a pensar en que la posibilidad de articular acciones para crear educar, es posible. En la medida en que se logre una confluencia de cada una de estas formas de comprender el mundo, las posibilidades de estas "maneras de hacer" en la realidad dialogan sin que se fragmenten, ratificando su pertinencia en la re-significación.

En los procesos desarrollados dentro de las PAC el lugar del artista va más allá de su capacidad creadora. Se convertirte en un actor más que hace parte de la comunidad, no solo porque es natal de Guatavita, sino porque su subjetividad encamina el proceso de mediación para resolver "artística y sensiblemente" el transcurso de la obra, dar respuesta creativamente a una serie de preguntas, y, sobre todo, pensar en cada uno de los actores para que la experiencia se vuelva transcendental y significativa para la subjetividad de estos. Al respecto, Paloma Blanco (2001) desde postulados de Suzanne Lacy, distingue el papel del artista dentro de las prácticas del arte público en cuatro roles que desempeña: el artista como experimentador, en tanto su mediación e interacción le permiten entrar en el territorio de un otro; el artista como informador (pues lo que hace es reelaborar la experiencia para narrar una situación); el artista como analista (ya que desde una práctica artística se analiza una serie de situaciones sociales); y el artista como activista (en una serie de circunstancias locales identificadas, el espectador se convierte en participante activo).

\section{En la construcción de un concepto de PAC}

Se ha insistido en que la pertinencia contextual y comunitaria dentro del desarrollo de la PAC con las mujeres participantes de Guatavita, radica en la re-significación que elaboraron en torno a su memoria individual y colectiva. A continuación se presentan varias reflexiones relacionados con la construcción del concepto de PAC que buscan aportar al tema desde el contraste que se ha venido haciendo entre algunas perspectivas teóricas y la experiencia en la práctica desde "Una mirada al ayer".

En un primer lugar, la cuestión de saber concretamente ¿qué son las PAC?, resulta problemático, en tanto las aproximaciones teóricas son diversas y sus productos disímiles y heterogéneos. Como se vio en el apartado inicial de este texto, para intentar acercarse al concepto de PAC se alude a nociones de otros "tipos de arte”, refriéndose a algunas de sus características y elementos para tomarlos “ prestados”. Por ejemplo, se habló del arte contextual y la relación de la obra con la realidad en la que se halla (Ardenne, 2006), del arte relacional y su carácter intersubjetivo (Bourriaud, 2006), del arte participativo y su razón de ser en la colaboración activa del espectador (Ardenne, 2006), del arte comunitario y su necesidad de vincular a un grupo social en su desarrollo (Palacios, 2009), del arte público y la relación que se establece con el espectador y el medio (Blanco, 2001; Lippard, 2001), o de la estética de la emergencia y sus posibilidades de intentar modificar el estado de las cosas desde lo colaborativo (Laddaga, 2006). Por esto se puede afirmar que no hay una noción certera que acote y defina con claridad el concepto de PAC.

En cuanto a las producciones de este tipo de prácticas artísticas ocurre algo similar que con su delimitación teórica. Siempre se alude al valor de la experiencia y lo procesual; por ejemplo, al referirse al arte contextual Ardenne (2006) asegura que este "tiene que ver con el tiempo de la confrontación inmediata y no renovable, tiempo de la tentación, de la acción y no de la contemplación. Se trata de subrayar esta característica propia del arte llamado 'en contexto real': su naturaleza 'procesual'. Más que formas (...), se le propone al espectador unos acontecimientos, una experimentación en vivo de lo dado" (pág. 35). En la mayoría de los casos, nunca se centra la atención en los recursos técnicos empleados o en los modos de hacer concretos de tipo de experiencias. Así, distinguir una serie de elementos propios para clasificar las PAC no es posible, pues en su impresión conceptual y de producción aparece la incapacidad para delimitarlas. 

No todas las experiencias en las que se implica al espectador entran a hacer parte de lo "comunitario" del arte. Muchas veces este tipo de prácticas se asocian al desarrollo de obras que permiten las relaciones sociales, ya sea dentro del museo o fuera de él. El arte relacional se basa en este supuesto del "intersticio social", donde "la obra se presenta como una duración por experimentar, como una apertura posible hacia un intercambio ilimitado" (Bourriaud, 2006, pág. 14), algo así como un "artefacto" que desde la interacción del público busca servir de pretexto para encontrarse. En esta medida, ¿qué obra de arte no permite el encuentro con el otro y con el mundo?, se puede decir entonces que una PAC no es la mera construcción de un dispositivo para permitir encuentros entre las personas, por el contrario, son construcciones colectivas que dan cuenta de la complejidad social en la que circula y se produce, donde el contexto en particular y lo intersubjetivo son elementos desde los cuales se estructura el proceso artístico.

Otro elemento problemático que resulta al definir la categoría de "comunidad" dentro del desarrollo de una PAC. La relativización del concepto en el campo artístico hace parte de esta dificultad; por ejemplo, Palacios (2009) desde Kwon y su texto "One Place after another. Site-specific and locational identity" del 2004, describe cuatro "posibles" tipos de comunidad desde las relaciones establecidas con un proyecto artístico: comunidad como categoría social, comunidad como grupo asentado en un lugar, y/o comunidad creada para realizar una obra de arte, en tanto desaparece o continúa. El concepto de comunidad se define desde la negación de una identidad común, para referirse a una "comunidad políticamente coherente" en donde existe una "autodefinición política” con relación a la opresión (raza, sexo, clase) dentro de una cultura compartida y una tradición discursiva.

En este mismo sentido, Lippard (2001) entiende que "comunidad no significa entenderlo todo sobre todo el mundo y resolver todas las diferencias; significa aprender a cómo trabajar dentro de las diferencias mientras estas cambian y se desarrollan" (pág. 69). Por otro lado también se dice que "actualmente la comunidad se ha convertido en el lugar en el que se interviene artísticamente (...) entendiendo que un territorio es un espacio físico pero también un conjunto de relaciones humanas y sociales" (Palacios, 2009, pág. 206). Con esto se puede decir que el lugar en tanto su noción contextual, dialoga con las diferencias que se encuentran en él, se muestra no solo como ese espacio físico para intervenir, sino para construir, pues son las mismas personas, incluido el propio artista, las que confieren conjuntamente el significado de comunidad, ya sea desde sus discontinuidades o desde sus particularidades como grupo dentro de su espacio y en una práctica artística.

El siguiente aspecto se vincula con el lugar del artista dentro del proceso creativo. Al referirse a la implicación del artista en el contexto, Ardenne (2006) asegura que "la experiencia se constituye en la inmediatez y en lo local. Exigiéndole al artista que se asiente en el espacio y el tiempo locales, esta experiencia requiere paralelamente unas prácticas tales como la observación, la agrimensura o la punción. El arte se convierte en práctica activa en tanto que reactiva (...), mientras que el artista se aplica para adaptarse al medio, para extraer de él un propósito o un posicionamiento divergentes e inéditos”. Por ello si se pretende generar comprensiones más profundas de lo que acontece en un lugar y los sujetos que lo habitan, es en la figura del mediador dentro del proceso donde se adopta una aproximación sensible, respetuosa e intencionada desde la reflexión ante ese contexto. En esta medida es recomendable que el artista sea parte de la comunidad o se vuelva parte e ella, en la medida que esto permite lograr una vinculación con el grupo humano en el cual actúa y puede llegar a facilitar los desarrollos artísticos, puede hacer parte del espacio-tiempo en el que se sitúa, además de fortalecer esos lugares en común entre su subjetividad y el medio, ayudan a que la obra sea mucho más pertinente para los actores.

En conclusión, las reflexiones anteriores, además de estar en construcción para el autor, intentan generar puntos de discusión en torno a la configuración de las PAC, discurso muy pertinente para el campo de las artes visuales en la actualidad. En este sentido, la pregunta por lo social, por la complejidad de los contextos, por los sujetos que actúan allí y por el hacer propio del artista-mediador, deben ser pensados desde este lugar, aspectos transversales de las PAC.

\section{Referencias}

Ardenne, P. (2006). Un Arte Contextual: Creación artística en medio urbano, en situación, de participación. (F. Mullier, Trad.) Murcia, España: Centro de documentación y estudios avanzados de arte contemporáneo.

Blanco, P. (2001). Explorando el terreno. En P. Blanco, J. Carrillo, J. Claramonte, \& M. Expósito, Modos de Hacer: arte crítico, esfera pública y acción directa (págs. 23-50). Salamanca, España: Ediciones Universidad de Salamanca.

Bourriaud, N. (2006). La Estética Relacional. Buenos Aires: Adriana Hidalgo Editora.

Castoriadis, C. (2007). La Institución Imaginaria de la Sociedad (Primera edición ed.). (A. Vicens, \& M. A. Galmarini, Trads.) Buenos Aires, Argentina: Tusquets Editores.

Eisner, E. (1998). Capítulo 1 ¿Por qué enseñar arte? En E. Eisner, Educar la Visión Artística (págs. 1-11). Barcelona, España: Paidós.

Halbwachs, M. (2004). La Memoria Colectiva. Zaragosa, España: Prensas Universitarias de Zaragoza.

Laddaga, R. (2006). Estética de la Emergencia. Buenos Aires: Adriana Hidalgo Editora.

Lippard, L. (2001). Mirando alrededor: dónde estamos y dónde podríamos estar. En P. Blanco, J. Carrillo, J. Claramonte, \& M. Expósito, Modos de Hacer: arte critico, esfera pública y acción directa (págs. 51-71). Salamanca, España: Ediciones Universidad de Salamanca.

Palacios, A. (2009). El arte comunitario: origen y evolución de las prácticas artísticas colaborativas. Arteterapia: Papeles de arteterapia y educación artística para la inclusión social, IV, 197. 211.

Romero, A., \& Giménez, M. (2005). Gestiones Artísticas: una Alternativa al Consumismo. Contratiempo (31), 11.

Vázquez, F. (2001). La Memoria como Acción Social: relaciones, significados e imaginario. Barcelona, España: Paidós Ibérica.

\section{David Ramos Delgado}

david.ramos.3@gmail.com - david.ramos.3@ hotmail.com

Licenciado en Artes Visuales de la Universidad Pedagógica Nacional, con beca de pregrado y distinción de Proyecto de Grado como Meritotio en proceso. Experiencia en el desarrollo de proyectos comunitarios y participativos desde el arte y en contextos concretos, al respecto debe destacarse su participación en la VII Bienal de Venecia de Bogotá.

Artículo recibido en mayo de 2012 y aceptado en diciembre de 2012. 